\title{
Book review: A.K. Samantara, S. Ratha: Materials Development for Active/Passive Components of a Supercapacitor
}

\author{
Springer Singapore, 2018, XI + 48 p., (ISBN: 978-981-10-7262-8) $58.84 €$
}

Rudolf Holze ${ }^{1}$ (1)

Received: 5 May 2021 / Revised: 5 May 2021 / Accepted: 6 May 2021 / Published online: 17 May 2021

(C) The Author(s) 2021

In electrical engineering, electronics, and electrochemical energy, technology supercapacitors are found almost everywhere. Started decades ago as passive components somewhat mysteriously called Gold Cap, they have developed and grown into much larger devices capable of starting a heavy truck or operating a tramway. Most likely, their further development will involve further areas of application; definitely, their numbers will increase strongly. Whether they will become a real substitute for secondary batteries is a question which engineers and users will answer several years from now. Currently, development-both evolutionary and revolutionary - of materials, combinations, processing, and production are tasks in laboratories worldwide.

In such a fluid situation, already preparation of a review article is a challenge and an enterprise with insecure outcome: Possibly the main conclusions or statements at the end of such report always assembled in time-consuming and attentiondemanding way are already dated on the day of publication and made obsolete by new developments. To write a book resembling such review paper on a larger scale (not much larger, because the book presented here has hardly more volume than an extensive review publication; actually, the page count is even smaller than the minimum suggested by the publisher of this series) is thus an even more dangerous task: the book might finally not even decorate library bookshelves because it was pushed aside by new reports and reviews.

Nevertheless, even such a book might have an inherent value and meaning because it provides guidance and an overview to the novice entering the field and the expert from time to time wishing to reassert her or his position by a look to the

Rudolf Holze

rudolf.holze@chemie.tu-chemnitz.de

1 Institut für Chemie, AG Elektrochemie, Technische Universität Chemnitz, 09107 Chemnitz, Germany left or the right for further options and possibilities. A closer look at the present volume shall answer the question whether the authors succeeded at this possible task or at the task they defined for themselves. Unfortunately - and this may be due to the challenge posed by the author's language which is sometimes hard to understand - the book's title is already somewhat ambiguous, and the first sentence of the preface (the place where the reader might expect the definition of the book's tasks and aim) only stresses this point: The book will deal with fabrication and working principle of electrochemical capacitors (presumably supercapacitors, but the authors do not waste time with precise definitions and systematic terminology). The authors move on to a section named "About the book." Somehow, this short text appears to be a repetition of things already said. And most likely, this text should have been placed on the back cover of the book.

The table of content provides some relief in this somewhat erratic-looking approach (but adds unfortunately to the confusion: The first item following the table of contents is not even mentioned in the said table: The item "About the Authors" again is usually placed on the back of a book or somewhere among the "front matter").

Finally, the reader arrives at the introduction. It starts with the $n$th repetition of by now generic texts about energy crisis and global warming as perceived by the authors with a picture from a historic text on European air quality. After some general ramblings, the authors conclude (among other things) that electric energy can only be stored in batteries, capacitors, and inductors. Somehow, they must have overlooked the very popular fact that the by far biggest fraction of electric energy storage is by pumped hydro. Moving on, things do not improve very much. Apparently, the authors have not seen many real supercapacitors. Otherwise, they would not have written such erroneous statements about supercapacitors in comparison to batteries like the claim that supercapacitors do not require bulky electrodes (whatever that means) and are therefore lightweight and non-toxic and 
have no disposal issues. This is presumably wrong on all counts. Most carbon-based (EDLC) supercapacitors have acetonitrile as the solvent in the electrolyte solution. And the electrodes are hardly different from those in a lithium-ion battery in appearance and bulky-ness.

After a brief historic background and a look at the present status in Chapter 2 (really brief, less than one page!), the authors move to the focus: Chapter 3 deals with components of supercapacitors, with electrode materials, electrolyte materials, current collectors, binders, and separators. It starts with some repetition and a classification of supercaps: EDLC-type, pseudo capacitors, and hybrid capacitors. This is rather strange, and hardly helpful. Neither is physico-chemical adsorption a synonym of redox reaction as stated in passing on $p$. 11. The more or less well-known authors quoted in support of this will not be amused, presumably. Following this somewhat disorienting introduction, the authors move on to carbonaceous materials. The rather obvious fact that several monographs collecting the state of the art have been published in recent years must have escaped the author's attention. After looking into them, some of the rather diffuse claims they make might have been avoided. The rather dim conclusions at the end of this section are too far away from demonstrated reality to merit further discussion. The next section deals with conducting polymers. Elsewhere, they are more precisely and certainly correctly called intrinsically conducting polymers, but once again, the authors of the present book waste no time on such details. In the end, more research is recommended, and the reader does not even know one redox reaction of one polymer illustrating the operating principle. But he has a lot of mostly dated references to find out for himself. The following section deals with metal oxides. Indeed, things have moved beyond $\mathrm{RuO}_{2}$, and there are literally thousands of reports on mixed metal oxides. The former fact has reached the authors in time; the latter must have escaped them. For reasons only the authors know, nitrides have earned their own section, and sulfides are simply forgotten. The final section appears to deal with composite materials, but suddenly, it turns towards carbon quantum dots. The end is slightly confusing.

The second major section of Chapter 3 is dedicated to electrolytes and electrolyte solutions. Once again, the authors become victims of their approach: A supercapacitor with an aqueous electrolyte solution will reach a cell voltage of $4 \mathrm{~V}$ only under very special circumstances. Without even hinting at this, the reader is simply left confused. How the use of organic solvents in electrolyte solutions increases thermal and cycling stability of a supercapacitor as claimed on $p .23$ remains a secret of the authors. Anyway, according to them and somewhat in contradiction to market realities, the outlook for organic electrolyte solutions seems to be dim. This pessimism is elevated to incredible heights at the start of the disproportionally long section on solid and gelled electrolytes. Definitely, such electrolytes making even the separator obsolete would be perfect- when available. Somehow, the authors manage to write for several pages on a subject, on which several reviews had been published recently, according to the authors' concluding statement in this section. Unfortunately, they forgot to provide the references.

Section 3 in this Chapter 3 handles current collectors. Certainly, many researchers treat the current collector only as a rather non-interesting necessity in their research of the active material which they have deposited on it. But-as the authors report by busily quoting a major review (which might be a good substitute for the present book) - for an actual device and even more for a commercially successful one, this detail merits attention. Whether gold foils or ITO plates will contribute to such success remains an open question. Whether the latter item helps to reduce costs appears to be unlikely given the rather tiny amount of indium resources we have. The conclusions of this short section are fairly diffuse, but certainly, the authors have drawn attention to a detail happily overlooked elsewhere.

The following section, section 4 , in chapter 3 is devoted to binders. As the authors rightfully point out, their function beyond keeping the active material together and sticking on the current collector is mostly unwelcome. They reduce the conductivity, add to dead weight, possibly decrease wetting, etc. Certainly, there is an argument for researchers to optimize binder content instead of copying the binder fraction of the most recently published previous publication. But this obvious suggestion is not found in this book; it has instead been made by the reviewer elsewhere after noticing with growing astonishment the lack of interest in this detail.

The final section, section 5, deals with separators. Certainly, they have an important role in preventing contact between the electrodes, but is facilitating electron transfer between them (presumably the electrodes, the English is a bit ambiguous here) really desirable? This very short section touches only on the obvious, and the hope to make separators redundant by using solid electrolytes is not even mentioned.

Chapter 4 covers asymmetric and hybrid supercapacitors. The first term seems to be well understood, but the term hybrid is a popular subject of confusion and misunderstanding. The description of the concept "hybrid supercapacitor" finally goes obviously completely astray: To claim, that the battery electrode (anode, presumably the negative one) acts as energy source whereas the cathode (the positive one, made of a capacitor material (?)) acts as the power source is simply incomprehensible or wrong or both. And in addition, in the publications known to the reviewer, the metal oxide is used as the positive electrode (i.e., the cathode, if this term is really preferred against all reasonable recommendation) whereas a carbonaceous material works as the negative electrode. With polypyrrole, matters are different; this polymer is also suitable as a negative electrode. Somehow misunderstood apparently by the authors is that actual assignment of a material to an 
electrode depends on the electrode potentials of the selected materials and the intended operating conditions. This is not the only misunderstanding. Somehow, the authors manage to mix up terms and concepts, even to contradict themselves. This is hardly helpful for a reader looking for guidance.

Finally, in chapter 5, trends etc. beyond traditional supercapacitors are discussed. The reviewer is lost: What is a traditional supercapacitor? Perhaps, the authors wanted to provide some help. The chapter starts with the almost offensive words "Primitive type supercapacitors ...", apparently naming EDLC devices. Most likely, the many manufacturers successfully making such devices do not even care about such judgment. Perhaps, the title of the chapter should have been "Beyond double layer capacitors"? Anyway, a confused mixture of arguments already made, concepts discussed before and rather arbitrary suggestions follows. The reader is advised to search for trends himself and find his own directions.

The text is generously decorated with mysterious items like "ITO plate" (p. 28) or flatly wrong statements like "because supercaps lack of energy density they are limited to backup devices" (p. 41). The former provides only a reason to speculate; the latter was wrong even at the time of writing the book's manuscript. The sometimes simply incomprehensible language is frequently sloppy. This may be entertaining, and there is indeed no obligation to write scientific texts in the uninspired and dry style of e.g. law books or software code. But it should, presumably must, be correct. The authors fail many times to meet this basic requirement. A few examples may help: On p. 6, it is claimed that "ceramic capacitors have been implemented in sophisticated electronic circuits as well as military grade applications." The present author has taken apart many old radios (and assembled new instrumentation), and ceramic capacitors were always present; the old radio never qualified as particularly sophisticated nor as military. The reference provided in support of this strange claim deals with a specific ceramic material — hardly a support for such broad claim. On the same page, the authors find a cathode and an anode in an EDLC supercapacitor. Presumably, the negative and the positive electrode, and contrary to the authors suggestion the device, is certainly polarized, already at the manufacturer's site. To assign the role "separated by an organic or aqueous electrolyte" as a function of the electrolyte solution is strange, in particular when noticing that the book contains a sub-chapter on separators, wherein the true separators are presented. This listing could be extended, presumably without adding new insights. The reader of a book might expect some entertainment value; she is definitely entitled to precise and correct language. This seems to have escaped the authors as well as the copy-editors.

Returning for a second to the introductory remark about publications in a very fluid field of research, it merits attention that the same authors presented a book on experimental aspects of supercapacitor research much less exposed to new developments. According to the bibliographic details (S. Ratha, A.K. Samantara: Supercapacitor: Instrumentation, Measurement, and Performance Evaluation Techniques, Springer, Singapore 2018), it promises a practical guidebook for the researcher. A review of this book will be made available to the reader elsewhere soon.

Whether extensive lists of references are useful in the present book may be a question of personal opinion. But when provided, references should be at least correct, complete, and up-to-date. And the lists should perhaps not make up 50\% of the page count of a chapter. To forget quoting reviews might help to shine a brighter light on the own work by simply ignoring the previous work of others. The reader of the present book might not appreciate this approach.

The book is generously illustrated with useful and less useful and even superfluous images. The language frequently borders at the incomprehensible; the novice will be lost and the reader familiar with the subject might smile only. Or both. The book will hardly be useful, and given the stiff price for a slim book, institutional and private bookshelves will most likely not see this book added.

\section{R. Holze, Chemnitz}

Funding Open Access funding enabled and organized by Projekt DEAL.

Open Access This article is licensed under a Creative Commons Attribution 4.0 International License, which permits use, sharing, adaptation, distribution and reproduction in any medium or format, as long as you give appropriate credit to the original author(s) and the source, provide a link to the Creative Commons licence, and indicate if changes were made. The images or other third party material in this article are included in the article's Creative Commons licence, unless indicated otherwise in a credit line to the material. If material is not included in the article's Creative Commons licence and your intended use is not permitted by statutory regulation or exceeds the permitted use, you will need to obtain permission directly from the copyright holder. To view a copy of this licence, visit http://creativecommons.org/licenses/by/4.0/.

Publisher's note Springer Nature remains neutral with regard to jurisdictional claims in published maps and institutional affiliations. 